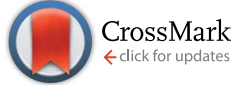

Cite this: RSC Adv., 2015, 5, 90111

Received 21st August 2015

Accepted 13th October 2015

DOI: $10.1039 / \mathrm{c} 5 \mathrm{ra16917h}$

www.rsc.org/advances

\section{Growth of dense CNT on the multilayer graphene film by the microwave plasma enhanced chemical vapor deposition technique and their field emission properties $\dagger$}

View Journal | View Issue

\author{
Atul Bisht, ${ }^{\text {ad }}$ S. Chockalingam, ${ }^{\text {a }}$ O. S. Panwar, ${ }^{\star a d}$ A. K. Kesarwani, ${ }^{\text {ad }}$ B. P. Singh ${ }^{\text {bd }}$ \\ and V. N. Singh ${ }^{\text {cd }}$
}

Catalyst assisted carbon nanotubes (CNTs) were grown on multilayer graphene (MLG) on copper and silicon substrates by the microwave plasma enhanced chemical vapor deposition technique. The transmission of the MLG was found to vary between 82 to $91.8 \%$ with the increase of deposition time. Scanning electron microscopy depicted that the MLG film survived at the deposition condition of CNTs with the appearance of the damaged structure due to the plasma. Growth of CNTs was controlled by adjusting the flow rates of methane gas. The density of carbon nanotubes was observed to increase with a higher supply of methane gas. It was observed that the field emission properties were improved with the increased density of CNTs on MLG. The lowest turn-on field was found to be $1.6 \mathrm{~V} \mu \mathrm{m}^{-1}$ accompanied with the highest current density of $2.8 \mathrm{~mA} \mathrm{~cm}{ }^{-2}$ for the CNTs with the highest density. The findings suggested that the field emission properties can be tuned by changing the density of CNTs.

\section{Introduction}

Graphene based films and carbon nanotubes have proved to drastically affect the futuristic technology due to their exceptional electrical, optical, thermal, chemical and mechanical properties. A hybrid nanomaterial comprised of both CNT and graphene may provide significant technological advancement in the areas of field emission, electrode materials, etc., due to the exploitation of the axial and planar directional properties. ${ }^{1}$ Recently, assembling of 1D CNT and 2D graphene to fabricate $3 \mathrm{D}$ nanostructures are of significant interest in the field emission, supercapacitor, water treatment etc. ${ }^{2-5}$ The hybrid material may be CNT rich or graphene rich depending on the amount of individual allotrope. Earlier single step method to grow CNT rich hybrid material has been reported. ${ }^{6,7}$ Nguyen et al. ${ }^{8}$ have synthesized CNT-graphene hybrid films on $\mathrm{Ni}$ by the low

${ }^{a}$ Polymorphic Carbon Thin Films Group, Physics of Energy Harvesting Division, CSIR-National Physical Laboratory, Dr K. S. Krishnan Marg, New Delhi-110012, India. E-mail: ospanwar@mail.nplindia.ernet.in; Fax: +9101145609310

${ }^{b}$ Physics and Engineering of Carbon Materials, Division of Materials Physics and Engineering, CSIR-National Physical Laboratory, $\mathrm{Dr}$ K. S. Krishnan Marg, New Delhi-110012, India

'Electron and Ion Microscopy, Sophisticated and Analytical Instruments, CSIRNational Physical Laboratory, Dr K. S. Krishnan Marg, New Delhi-110012, India ${ }^{d}$ Academy of Scientific and Innovative Research (AcSIR), CSIR Campus, New Delhi110012, India

$\dagger$ Electronic supplementary information (ESI) available. See DOI: $10.1039 / \mathrm{c} 5 \mathrm{ra} 16917 \mathrm{~h}$ vacuum annealing of cellulose acetate and showed that the hybrid film exhibited the substantial improvement in the optoelectrical and field emission properties compared to their individual counterpart. CNT has already been proven as a promising field emitter. ${ }^{9-11}$ A large number of voids are presented in the CNT networks, which reduce the overall conductivity of the CNTs. ${ }^{2}$ The thermal conductance of multi wall CNT (MWCNT) is $\sim 3000 \mathrm{~W} \mathrm{~m}^{-1} \mathrm{~K}^{-1}$ which is reduced to $\sim 20 \mathrm{~W} \mathrm{~m}^{-1}$ $\mathrm{K}^{-1}$ or lowers in the mat and forest nanotube structure due to the discontinuity in the homogeneous bottom contact of CNTs. ${ }^{12}$ In the same way, the electrical conductivity is also affected in the CNT mat or forest, deposited at any substrate. ${ }^{\mathbf{1 2}}$ The interconnection of the individual CNT (in the mat or forest) by the MLG film may provide better electron transport for the field emission application. Although there are chemical methods to synthesize graphene-CNT hybrid film, but these are not suitable as field emitter. ${ }^{\mathbf{1 3}}$ Synthesis of hybrid material on the metallic substrate provides the better electron transport, enhanced the bonding between the substrate and film, which resolved the peeling off problem during field emission. The stability of combination as well as the conduction of internal electrons in graphene-CNT is better than other composite due to the isomeric similarity between the CNT and graphene. ${ }^{14} \mathrm{Kim}$ et $a .^{4}{ }^{4}$ have reported out of plane growth of CNTs on graphene assisted by the Ni nanoparticle and found an application for the supercapacitor.

Among the various methods used for the graphene synthesis, chemical vapor deposition (CVD) has proved to synchronize 
graphene from the lab scale to industrial processes..$^{15,16}$ Currently CVD technique used temperature of $\sim 1000{ }^{\circ} \mathrm{C}$ to synthesize graphene on copper. In this scenario, the game changing breakthrough may be the synthesis of graphene at low temperature with the reduced time of synthesis. Plasma enhanced CVD (PECVD) is considered as a promising technique to synthesize graphene based film at low temperature with the rapid growth due to the presence of a rich chemical environment consisting of radicals, molecules, ions. ${ }^{17,18}$ The plasma also induced breaking of the precursor hydrocarbon and a detachment of hydrogen at low temperature. Although the quality of CVD grown graphene is very high, at the same time PECVD grown graphene based film may find application in various fields. The electrical property of the PECVD grown graphene based film is inferior to other graphene based film which prohibited their use in electronic applications. ${ }^{19}$ Microwave PECVD is a versatile technique by which various carbon based nanostructures e.g., nanodiamond, carbon nanotubes, graphene (vertical or horizontal) can be grown by changing the various deposition parameters as the deposition substrate, precursor, deposition pressure, temperature etc. ${ }^{\mathbf{2 0 - 2 3}}$ Although there have been reports of SiC assisted, single step growth of the tubular grievance cone-CNT hybrid, the deposition time is quite high for the whole process. ${ }^{24}$ In such process, the edge of graphene based structure, e.g., onion-like and bowl-like acts as an incorporation site for the carbon adatoms. The single step process is versatile as the precursor SiC can be grown on any substrate and is free from the metal catalyst, which is not possible for the two step process. In a two step process, the density of CNTs can be controlled by controlling the catalyst nanoparticles.

Additionally, due to the $\pi-\pi$ interaction between the two allotropes, CNT and graphene, low contact resistance provides the hybrid material as a promising material for field emitter. ${ }^{25}$ Das et al. ${ }^{26}$ have also measured the field emission properties of the self-organized hybrid film with MLG consisting of $\sim 40$ layers and studied their field emission properties with bending. The transmittance and field emission properties of the hybrid films can be tailored by altering the CNT density.

In this work, we have synthesized MLG-CNT hybrid films by a two-step method on copper and Si substrate and studied their field emission properties. Raman spectroscopy, optical image and scanning electron microscopy (SEM) are performed to confirm the growth of the CNT-MLG hybrid on copper and Si substrate. The appearance of transferred MLG film on the Si wafer with the post CNT deposition confirms that the graphene has not been etched during the CNT deposition due to its multilayer structure and short deposition time.

\section{Experimental details}

The MLG film was grown on the commercially available $\mathrm{Cu}$ foil of $50 \mu \mathrm{m}$ thickness with a purity of $99.999 \%$ by the MW PECVD technique. The deposition temperature was $\sim 700{ }^{\circ} \mathrm{C}$ and the deposition pressure was $5.5 \times 10^{-2}$ Torr. We have used $1200 \mathrm{~W}$ microwave power in all the depositions and optimized the reflected power which is the same for all the depositions, using the stub tuners in our microwave system. In our system configuration, at low microwave power we have found that it is difficult to sustain the plasma at very low pressure and high pressure, so, we have used full microwave power and the power has been the same in all the depositions. The foil was cleaned with the isopropanol and acetone and before depositing the film, the foil was treated for 5 minutes by $\mathrm{Ar}+\mathrm{H}_{2}$ plasma to remove the remaining native oxide of $\mathrm{Cu}$ before depositing the film. The deposition time was varied from $30 \mathrm{~s}$ to $2 \mathrm{~min} . \mathrm{C}_{2} \mathrm{H}_{2}$ gas was used as a carbon precursor. Before injecting $\mathrm{C}_{2} \mathrm{H}_{2}$ gas, the plasma was stabilized with the help of $\mathrm{Ar}$ and $\mathrm{H}_{2}$ gas. The gas flow rate of $\mathrm{C}_{2} \mathrm{H}_{2}$, Ar and $\mathrm{H}_{2}$ during MLG growth was 5, 20 and $20 \mathrm{sccm}$, respectively. After the growth, the temperature was cooled naturally to room temperature. The synthesized MLG film was transferred to the Si wafer. Copper was etched chemically by $\mathrm{FeCl}_{3}$ without a coating of poly methyl methacrylate (PMMA). We have used $1 \mathrm{M} \mathrm{FeCl}_{3}$ solution for copper etching. The MLG film was lifted from the $\mathrm{FeCl}_{3}$ solution and treated with the deionized water twice before transferring to the wafer. Due to the multilayer, graphene sustained the transferred process, whereas, the single layer graphene is too fragile that it cannot be transferred without the PMMA coating.

Further to grow CNT, the MLG film transferred to the Si wafer and MLG film grown on copper was loaded into the thermal evaporation system. A thin film of nickel $(\sim 10 \mathrm{~nm})$ was grown on MLG film, both on the Si wafer and copper substrate. Further, the substrates with the Ni film and MLG were loaded to the MW PECVD system. The thin Ni film was converted to Ni nanoparticle by the heat treatment, while the stresses were caused by the thermal expansion during deposition. We have not given any separate treatment to form Ni nanoparticle. The nanoparticles have been formed by the heat treatment, which we have used during the deposition. The CNT was grown on the MLG film with the help of Ni nanoparticle at a high pressure of $\sim 20$ Torr and $600{ }^{\circ} \mathrm{C}$. The gas flow rate of $\mathrm{Ar}$ and $\mathrm{H}_{2}$ was fixed to 20 and $50 \mathrm{sccm}$, respectively, in all the deposition for CNT synthesis. The flow rate of methane for CNTs deposition was kept as 10, 20 and $30 \mathrm{sccm}$. The deposition time for the CNTs growth was $5 \mathrm{~min}$. Due to the plasma treatment at high temperature, the MLG film was changed to the wrinkled MLG. The schematic of the growth process is shown in Fig. 1.

The MLG film and CNT grown on the MLG films were characterized by the Raman spectroscopy, ultraviolet-visible (UV) spectroscopy, scanning electron microscopy (SEM) and transmission electron microscopy (TEM). The Ni nanoparticles were characterized by the SEM and the particle distribution size was calculated by the Image $\mathrm{J}$ software. The structure and bonding information of the samples were studied by the Raman spectroscopy (Renishaw, micro-Raman model in Via Reflex) with $514 \mathrm{~nm}$ laser excitation at room temperature. The transmission of MLG film was measured on corning glass by UVvisible spectrometer (Shimadzu UV-3101). The morphology and microstructure of the samples were examined by the scanning electron microscope (JEOL-JSM-7100F). The field emission measurements were carried out with a diode configuration using an indigenously developed field emission measurement setup. The CNT on the MLG film on copper 


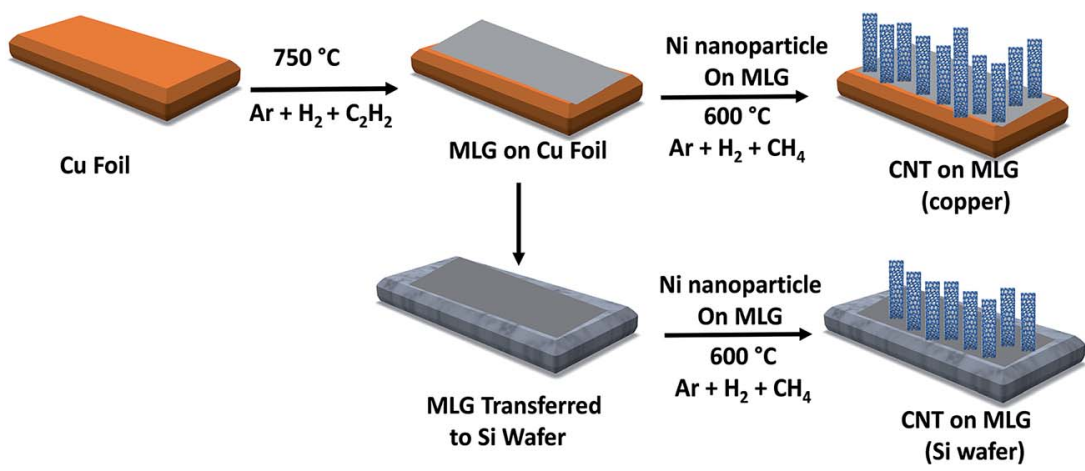

Fig. 1 Schematic diagram of the CNTs film growth on the MLG film.

substrate was used as a cathode and indium tin oxide (ITO) coated glass acted as an anode. The field emission measurements were carried out with the help of Keithley 2410 source meter through an IEEE card. The separation between the anode and cathode is defined by the PTFE spacer of thickness $150 \mu \mathrm{m}$ and the overlap area between the plate anode and cathode was kept $\sim 0.196 \mathrm{~cm}^{2}$. The current-voltage $(I-V)$ characteristics were studied at room temperature under a vacuum $\sim 3 \times 10^{-7}$ Torr. These measurements were fairly repeatable and reproducible on the same sample at different locations. The emission current density $(J)$ was calculated by dividing the emission current $(I)$ by the area of the cathode which is defined by the area of the hole in the spacer. The electric field $(E)$ was defined by the voltage drop across the vacuum gap.

\section{Results and discussions}

\subsection{Surface morphology}

Fig. 2 shows the optical image of the MLG film grown on the copper substrate. The optical image of the MLG film on copper

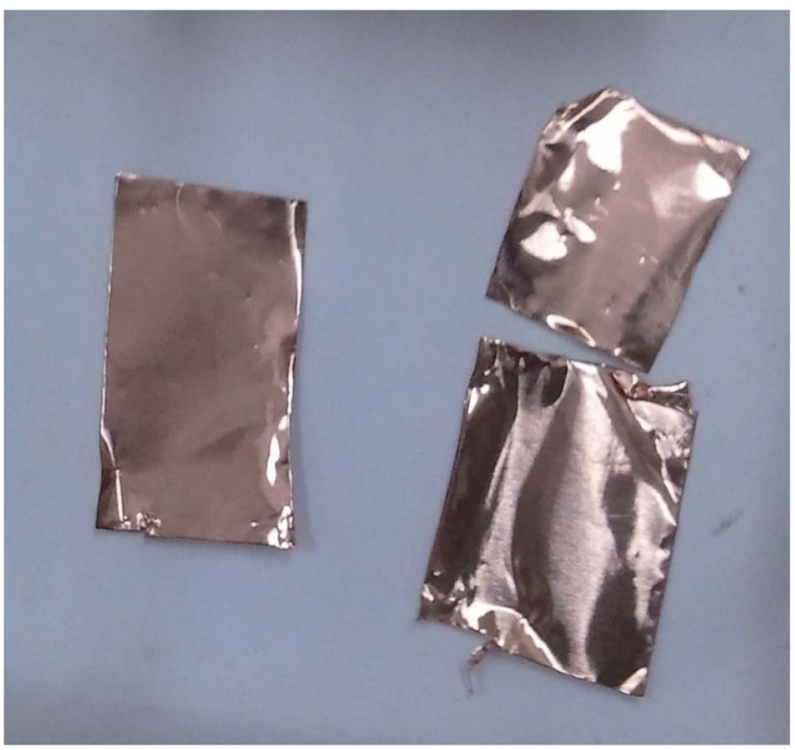

Fig. 2 Copper foil with the MLG grown by the MW PECVD technique at low pressure. for etching in $\mathrm{FeCl}_{3}$ solution and subsequently transferred to the DI water is also shown in Fig. 3. Fig. 4(a) shows the MLG film transferred to the Si wafer, during deposition at high temperature and in the presence of plasma, which revealed that the MLG film is sustained during the deposition process. The optical images of the CNT grown on the copper and Si substrate are also visible as the black appearance as shown in Fig. 4(b) and (c), respectively. This black appearance shows the growth of the dense CNTs on graphene. As the nanoparticles have not been grown throughout the MLG film on $\mathrm{Cu}$, so the dense CNTs are appearing only in the region where $\mathrm{Ni}$ nanoparticles were grown. The appearance of the MLG film along with CNT on Si wafer shown in Fig. 4(b) and (c), confirms that the deposition conditions used did not etch the MLG film.

Fig. 5(a) shows the SEM micrograph of MLG transferred to a Si wafer before being inserted into the plasma. The MLG and Si wafer are visible individually in the SEM micrograph. It is clear from the Fig. 5(b) that the plasma treatment has damaged the MLG film, but not etched the film completely. Fig. 6(a) depicts the nanoparticles of $\mathrm{Ni}$ obtained by annealing the thin nickel film. The particle size distribution of the nanoparticles has been calculated by the freely available Image J software. The maximum probable radius of the nanoparticles is within the range up to $10 \mathrm{~nm}$ as shown in Fig. 7. The radius statistics of the nanoparticles is shown in Fig. 7. Fig. 6(b)-(d) show the SEM micrographs of the CNTs grown on the MLG film at different methane flow rates of 10, 20 and $30 \mathrm{sccm}$, respectively. At the higher magnification in SEM, the simultaneous imaging of the graphene step and the CNT film was not possible, so the individual images of the MLG film and CNTs film are shown in Fig. 5 and 6(b)-(d). Graphene/graphite sheets can sustain high temperature in an inert environment and help to suppress the agglomeration of the Ni nanoparticle. ${ }^{27}$ At high temperature of $\sim 800{ }^{\circ} \mathrm{C}$, graphene can be etched away to give etched pits, due to the hydrogenation in the presence of $\mathrm{Ni}\left(\mathrm{Ni}_{\text {nanoparticle }}+\right.$ $\mathrm{C}_{\text {graphene }}+2 \mathrm{H}_{2}=\mathrm{Ni}_{\text {nanoparticle }}+\mathrm{CH}_{4}$ ), so the CNTs have been grown at low temperature of $600{ }^{\circ} \mathrm{C}^{28}$ The deposition process of CNTs has not totally etched away the graphene as shown in the SEM micrographs of the hybrid film after the CNT deposition and the optical image of the MLG on silicon wafer during deposition. This may be due to the low deposition temperature process, multi-layer structure of graphene and short time 

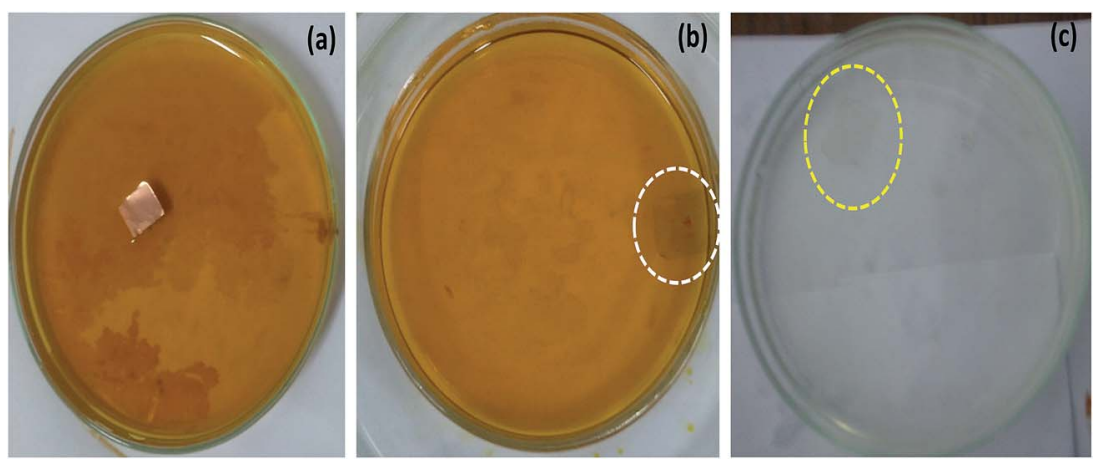

Fig. 3 (a) MLG film on copper in $\mathrm{FeCl}_{3}$ solution for etching, (b) $\mathrm{MLG}$ film floating in $\mathrm{FeCl}_{3}$ solution after copper etching and (c) $\mathrm{MLG}$ film transferred to the DI water.

deposition. However, the etched pits and lines which are appearing in the SEM images after the growth as shown in Fig. 5(b) may be due to the plasma effect. Fig. 6(b)-(d) show the SEM micrographs of CNTs films deposited on MLG at different $\mathrm{CH}_{4}$ gas flow rates. All the micrographs are showing tangles, spaghetti-like CNT network. CNTs are densely packed and uniformly coated due to the high density of the $\mathrm{Ni}$ nanoparticles. The density of CNTs is changing with the change of methane flow rate from 10 to $30 \mathrm{sccm}$. The deposition time has been fixed for $5 \mathrm{~min}$. For all the samples, CNTs have been grown with a lower density at the lowest methane flow rate $(10 \mathrm{sccm})$. Along with the CNTs, Ni nanoparticles are also appearing in Fig. 6(b). The nanoparticles have been encircled with the dotted lines in Fig. 6(b). The density of CNTs is enhanced with the increased carbon feedstock i.e., with an increasing methane gas flow rates as depicted in Fig. 6(c and d). The inset in Fig. 6(d) is showing the side-view image of the film. The height of CNTs appears to be $\sim 400 \mathrm{~nm}$ from the inset shown in Fig. 6(d). For the catalyst shaping to grow CNTs catalytically, the substrate material should have a low surface energy and should not be contaminated with the catalyst nanoparticle. ${ }^{29}$ On this view, graphene is a perfect substrate due to its low surface energy and high thermal stability. ${ }^{29}$ Recently, such a two-step process for the growth of CNT-graphene hybrid films has drawn much interest. Lee et al. ${ }^{29}$ have also fabricated Fe nanoparticle, which
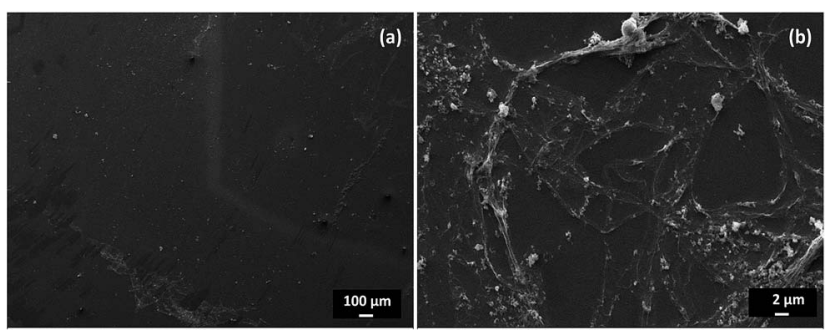

Fig. 5 SEM micrographs of the MLG film transferred to the Si wafer (a) before deposition and (b) after being treated at high temperature in the plasma during deposition.

promoted CNT in the graphene oxide film at $600{ }^{\circ} \mathrm{C}$ by the PECVD technique. Dong et al. ${ }^{30}$ have synthesized the hybrid material by decorating $\mathrm{Cu}$ foil by the silicon nanoparticle and observed simultaneous growth of graphene on the foil with CNTs on silicon nanoparticles, but they have to grow as uniform and continuous CNT network.

For the TEM, the graphene and CNTs have been transferred to the carbon coated copper grid by etching the substrate in $\mathrm{FeCl}_{3}$ solution. Fig. 8(a and b) shows the TEM of the MLG sheet and the CNTs. The MLG film is showing the crumpled structure due to the transfer process. The thick sheet appearing in the TEM micrograph is confirming the multilayer structure. The
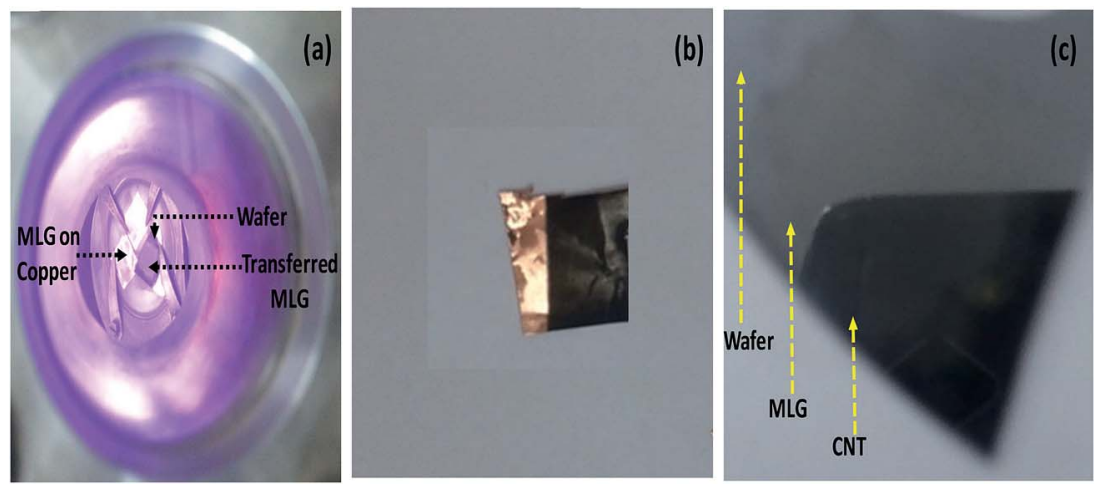

Fig. 4 (a) MLG on copper and silicon substrates during CNT deposition, (b) CNT on MLG film directly on copper and (c) CNT on transferred MLG film on Si wafer. 

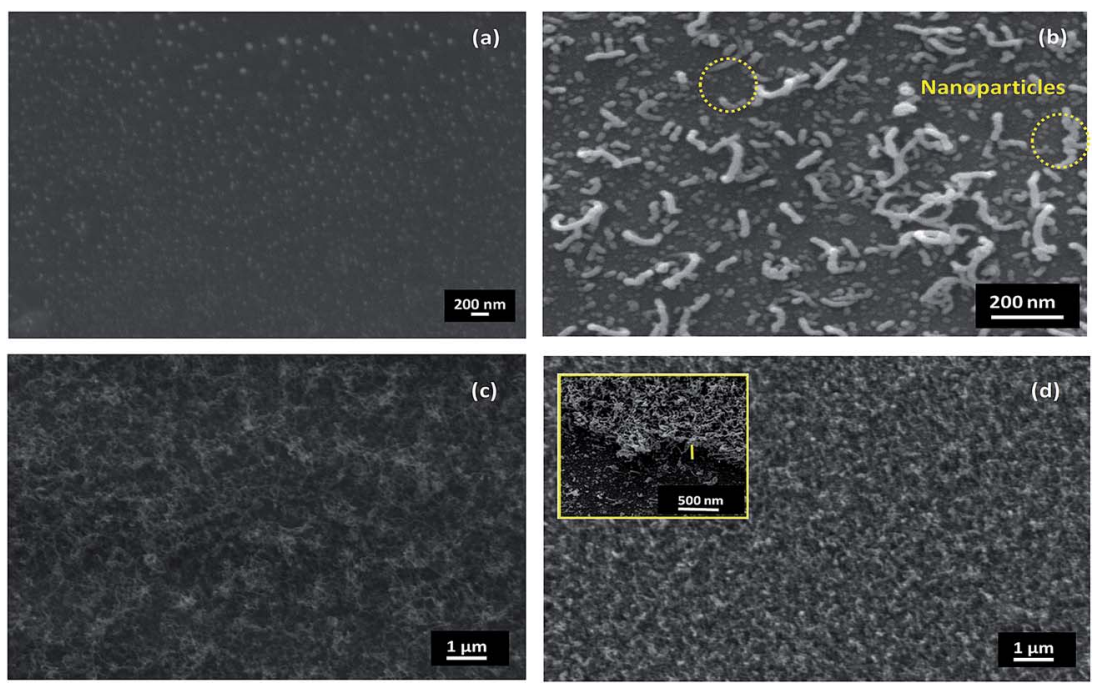

Fig. 6 SEM micrographs of (a) Ni nanoparticle and CNTs grown on the MLG film at different flow rates of methane of (b) $10 \mathrm{sccm}$, (c) $20 \mathrm{sccm}$ and (d) $30 \mathrm{sccm}$ (inset showing side-view SEM).

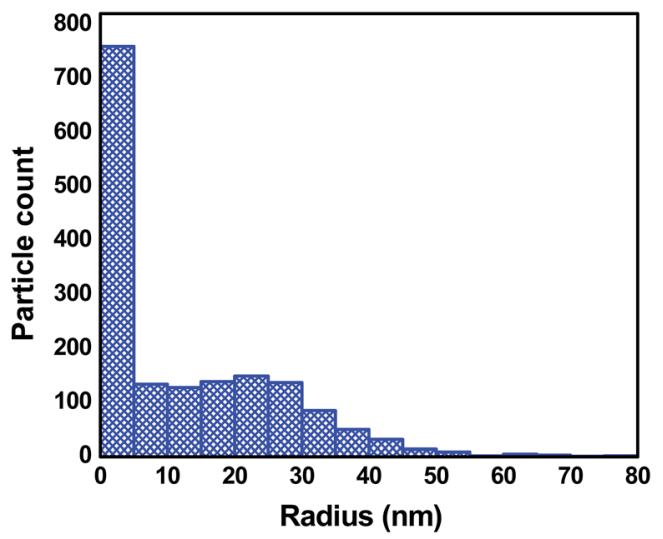

Fig. 7 Particle size distribution of Ni nanoparticles calculated by the Image J software.

high resolution TEM image of the CNTs is shown in Fig. 8(c). The graphitic edge of CNTs with the interlayer distance of 0.34 $\mathrm{nm}$ is clearly visible in Fig. 8(c). The diameter of CNT is found to be $\sim 10 \mathrm{~nm}$ from the HRTEM image of the CNTs. Fig. 8(d) shows the HRTEM image of one side of CNT and the interplaner spacing has been calculated by the software provided by the Gaten microscopy, confirming the interplaner spacing of 0.34 nm.

\subsection{Growth mechanism}

The growth of graphene in the PECVD technique is a competitive process in which there is a competition between the growth by the carbon radicals and etching of amorphous or disordered carbon by the atomic hydrogen. ${ }^{18}$ Kalita et $a l .{ }^{17}$ have proposed that during the growth of graphene in the PECVD technique, carbon radicals present in the plasma are continuously absorbed on the $\mathrm{Cu}$ surface and bind together in the $\mathrm{sp}^{2}$ bonded graphene film by the diffusion process. In contrast to the Ni and
$\mathrm{Co}$, the temperature required to dissolve carbon on the $\mathrm{Cu}$ lattice is very high $\sim 2700{ }^{\circ} \mathrm{C}$. This temperature is very high compared to the maximum temperature needed for the growth of graphene on $\mathrm{Cu}$ at $\sim 1000{ }^{\circ} \mathrm{C}$. $\mathrm{Cu}$ has the lowest carbon affinity to form a carbide phase $\left(0.001-0.008 \%\right.$ wt at $\left.1084{ }^{\circ} \mathrm{C}\right) .{ }^{31}$ The absorption-decomposition mechanism is responsible for the graphene growth on $\mathrm{Cu}$ lattice rather than the dissolutionprecipitation mechanism in the $\mathrm{Ni}$ and $\mathrm{Co}$ metal. ${ }^{32} \mathrm{Cu}$ is an important substrate for a single layer graphene deposition by the CVD technique as copper acts as a catalyst for the hydrocarbon dissociation. The MLG growth is possible in the plasma based technique as the carbon radicals are generated by the plasma and have no much effect of the substrate. The carbon radicals with hydrogen detachment induced by the microwave plasma formed $\mathrm{sp}^{2}$ carbon film on the copper substrate. ${ }^{17}$ The low temperature growth of MLG even at $240^{\circ} \mathrm{C}$ is possible in the plasma based techniques as carbon atoms or radicals are supplied by the plasma, and there is not much effect of the substrate. ${ }^{17}$ The Ar assisted smooth, uniform plasma and high carbon radical density induced by the microwave provides MWPECVD as a rapid growth process. Due to the initial low mass thickness, the as deposited Ni thin film is deposited in the form of discontinuous islands. The discontinuous $\mathrm{Ni}$ island film contains particles with the high surface coverage in the form of the particles of irregular shape. In the annealing step during the deposition, the discontinuous irregular islands transform into the regular spherical shape nanoparticle with the low surface coverage. ${ }^{33}$ Catalyst nanoparticles with a diameter of several tens of nanometers are critical to grow CNTs. The particle size distribution has been given in Fig. 7, which gives the radius of nanoparticles, not the diameter of nanoparticles. The diameter of CNTs depends upon the size of catalyst nanoparticle and below a critical size single CNT is grown on the single nanoparticle. At the same time, several CNTs can grow on the catalyst nanoparticle with the larger size. ${ }^{34}$ The statement in the manuscript does not reflect that most of the Ni nanoparticles do 

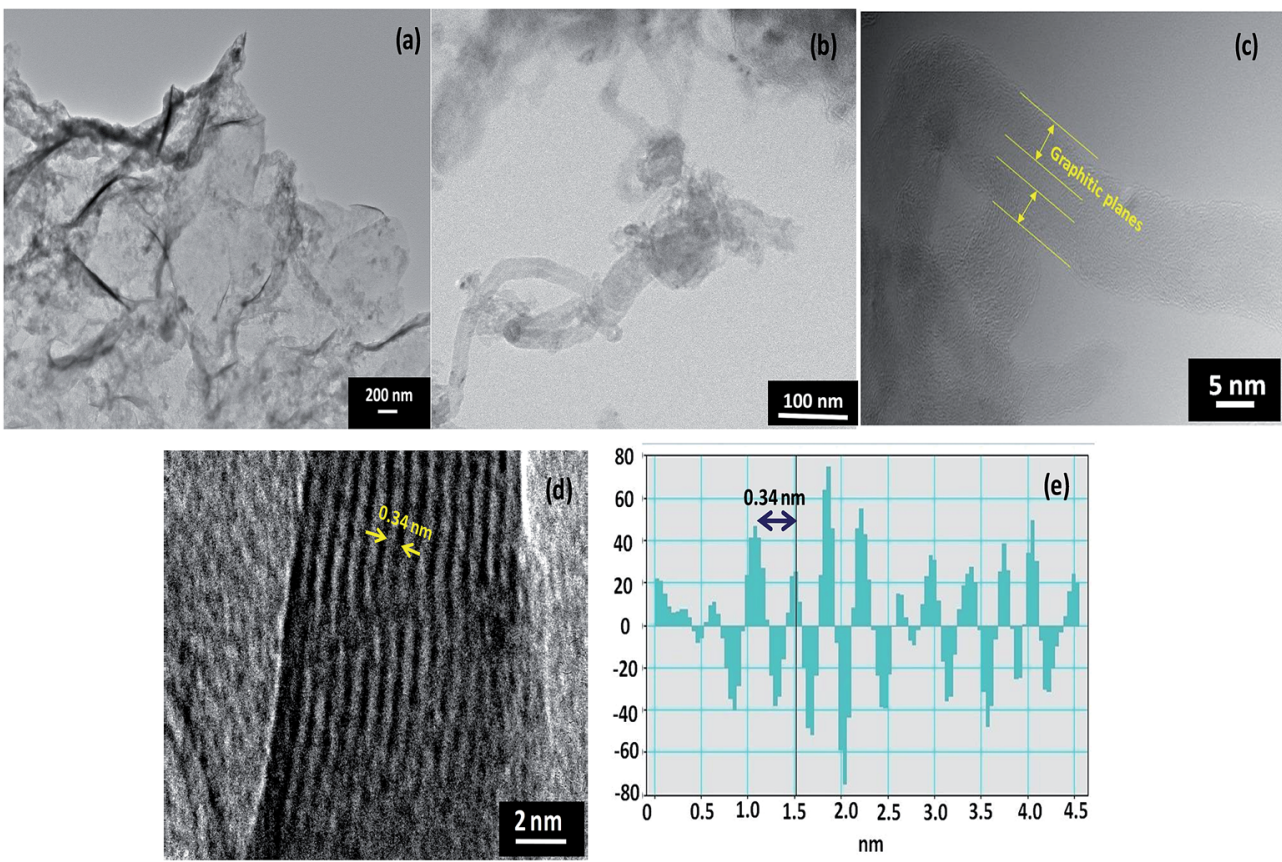

Fig. 8 TEM micrographs of (a) MLG film, (b) CNTs, (c) HRTEM image of CNT, (d) HRTEM image of graphitic planes of one side of CNT and (e) interplaner distance $(0.34 \mathrm{~nm})$ calculated by the Gaten microscopy software.

not participate in the growth of CNTs. The process is different for the small catalyst nanoparticle $(<20 \mathrm{~nm})$, large nanoparticle $(>100 \mathrm{~nm})$ and intermediate nanoparticle. For the small catalyst nanoparticle $(<20 \mathrm{~nm})$, surface diffusion of carbon atoms dominates due to the large surface area to volume ratio, for the larger catalyst particle (>100 nm) bulk diffusion dominates and for the intermediate nanoparticles (between 20 to $100 \mathrm{~nm}$ ) both the processes may occur. ${ }^{35}$ Transition metal acts as a catalyst for the CNT growth by the vapor-solid interaction process. Instead of the smooth and continuous film, catalyst metals in the form of nanoparticles are necessary for the CNT growth. ${ }^{36}$ The hydrocarbon precursor, radicals, ions, etc., in the plasma adsorbed on the catalytic nanoparticle surface, released carbon which diffuses and dissolves into the catalyst nanoparticles. After reaching the supersaturating state, the dissolved carbon atoms precipitate out of the catalyst nanoparticles in the form of tubular carbon nanotubes. ${ }^{36}$

The microwave energy is consumed in $\mathrm{H}_{2}$ vibrational mode, translation-rotation mode of heavy species and activation of chemical process due to the interaction of electrons to heavy species. $^{37}$ At lower microwave power densities, molecular hydrogen is not dissociated efficiently. At high microwave power, the concentration of atomic hydrogen $[\mathrm{H}]$ and $\mathrm{H}$ energy increases to a much higher value. The increase of atomic hydrogen density enhances the hydrocarbon dissociation via the successive dehydrogenation process. Under these conditions, the high energetic atomic hydrogen immediately etches the defects away and saturates the surface for further bonding. ${ }^{38}$ At the same time, other surfaces are activated and bond with other species from the plasma. ${ }^{38}$ There is a competitive phenomenon between these two processes, namely etching and deposition. The atomic hydrogen is also responsible for the $\mathrm{sp}^{2}$ bonded carbon atoms which in turn etch the graphene film. This is clear from the SEM micrograph in Fig. 5(b) that graphene film has been etched away in some region. As we have used MLG, so the graphene is sustained after interaction with the atomic hydrogen.

\subsection{Raman spectroscopy}

Fig. 9 shows the Raman spectra of MLG film on the copper deposited for different times. All the samples show a disorder induced $\mathrm{D}$ band at around $1350 \mathrm{~cm}^{-1}$ due to the phonon scattering at the defective site and impurities. The $\mathrm{D}$ band is generally absent or weak in the graphite or high quality graphene. The $\mathrm{G}$ band with a peak position varying from $\sim 1590$ to $1600 \mathrm{~cm}^{-1}$ originates due to the $\mathrm{E}_{2 \mathrm{~g}}$ in plane vibration of the $\mathrm{sp}^{2}$ carbon atoms. A second order $2 \mathrm{D}$ band occurs with the position varying from 2690 to $2697.9 \mathrm{~cm}^{-1}$ and $\mathrm{D}+\mathrm{G}$ band occurs at $\sim 2940 \mathrm{~cm}^{-1}$. The difference between the Raman spectra of MLG and graphite is the shape of the $2 \mathrm{D}$ band. In the MLG, the $2 \mathrm{D}$ band is symmetric, whereas, in the graphite the $2 \mathrm{D}$ band is nonsymmetric with a shoulder appearing in the left. The D peak is prominent in all the samples which may be correlated to the non-coalescence of the graphene domains as D band is associated with the edge defects and the direct exposer to the plasma also affects adversely the graphene film. ${ }^{23}$ The quality of $\mathrm{Cu}$ substrate also affects the graphene film growth as it is preferably a defect free and smooth $\mathrm{Cu}$ substrate, which is achieved in multi-steps e.g. electroplating, annealing, etc. This may also be the reason for the prominent D peak as the MLG film is grown in a single step. Such type of Raman spectra with the prominent $\mathrm{D}$ peak is an important spectral feature of the graphene film 

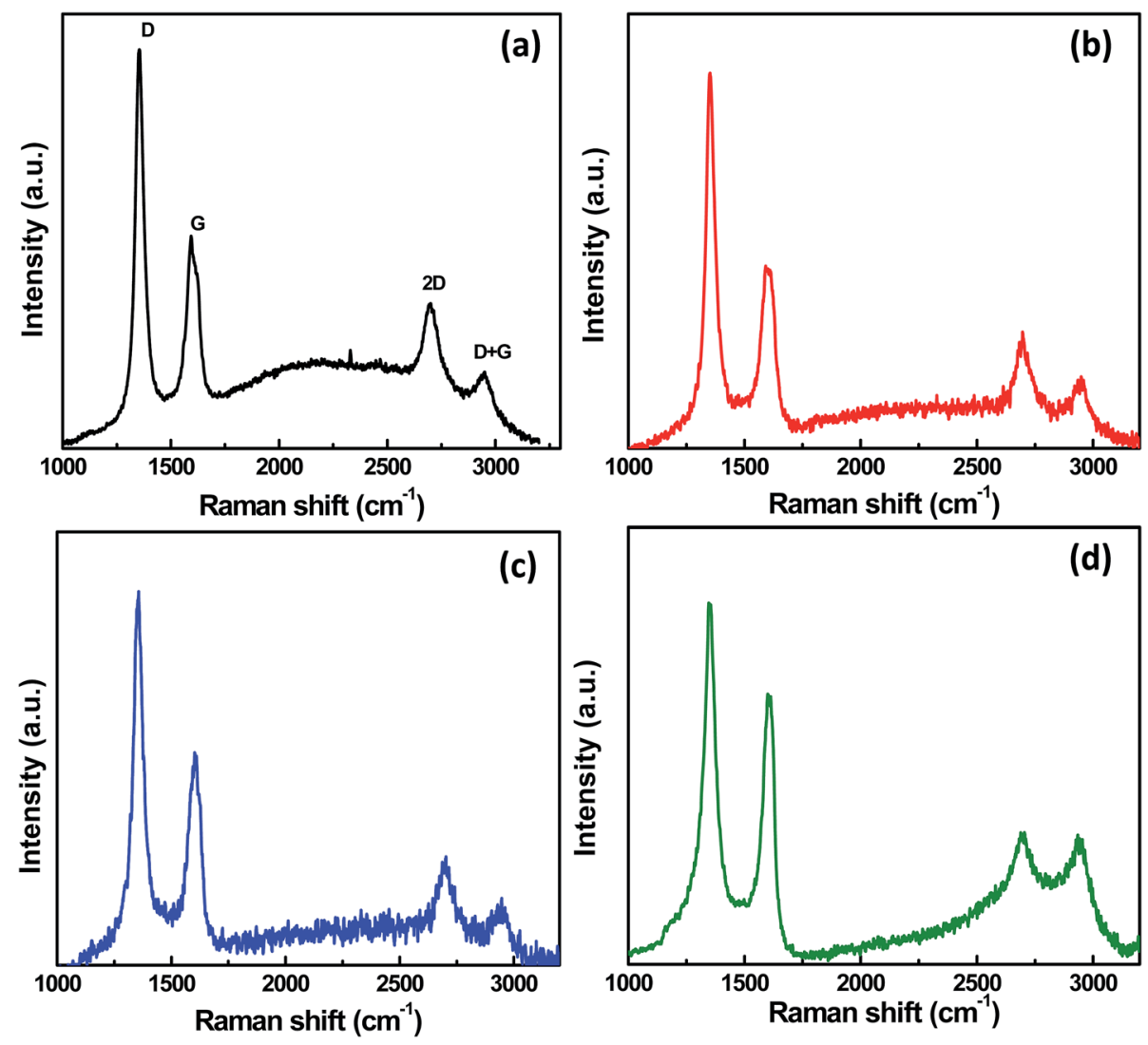

Fig. 9 Raman spectra of the MLG film grown on copper for different deposition times of (a) $30 \mathrm{~s}$, (b) $60 \mathrm{~s}$, (c) $90 \mathrm{~s}$ and (d) $120 \mathrm{~s}$.

grown by the PECVD technique at low temperature. ${ }^{18}$ The high amount of defect density in the PECVD grown graphene is due to the energetic particle from the plasma interacting with the growing graphene surface. ${ }^{23}$ To remove this problem, a certain distance is maintained between the plasma and the deposition stage. ${ }^{23}$ The $I_{\mathrm{D}} / I_{\mathrm{G}}$ ratio has been found to be 1.9, 2.0, 1.7 and 1.3 for the sample deposited at different times, respectively. The number of graphene layers can be calculated from the intensity ratio of $2 \mathrm{D}$ and $\mathrm{G}$ band. The $I_{2 \mathrm{D}} / I_{\mathrm{G}}$ ratio is varying from 0.70 to 0.45 with the increase of deposition time from $30 \mathrm{~s}$ to $2 \mathrm{~min}$. $\mathrm{D}+$ $\mathrm{G}$ band is also due to the defects in $\mathrm{sp}^{2}$ sites and graphene domain edge in the MLG film. ${ }^{17}$ The $I_{2 \mathrm{D}} / I_{\mathrm{G}}$ ratio is showing that the numbers of layers are varying in the range of 6-10. Panwar et $a l .^{39,40}$ have reported graphene by the filtered cathodic vacuum arc technique using a solid source with $I_{2 \mathrm{D}} / I_{\mathrm{G}}$ ratio varying between 0.42 to 0.47 by annealing the amorphous carbon film of $3-6 \mathrm{~nm}$ thick at $750{ }^{\circ} \mathrm{C}$ and calculated the number of layers as $4-5$. Origin of the similar $D+G$ band is a feature of the Raman spectra of MLG film deposited by the plasma based techniques. ${ }^{17,41}$ Although high intensity of D peak shows that the quality of graphene film is not so good compared to the CVD grown graphene but Kim et al. ${ }^{\mathbf{4 1}}$ have demonstrated that the capacitive touch panel can be realized with similar graphene film. Fig. 10 depicts the Raman spectroscopy of CNT grown on MLG film on copper substrate deposited with $\mathrm{CH}_{4}$ gas flow rate of $20 \mathrm{sccm}$. The $\mathrm{D}, \mathrm{G}$ and $2 \mathrm{D}$ peak have positions at 1346, 1603 and $2693.5 \mathrm{~cm}^{-1}$, respectively. The $I_{2 \mathrm{D}} / I_{\mathrm{G}}$ ratio has significantly decreased to 0.26 for the CNTs grown on the MLG with $\mathrm{CH}_{4}$ gas flow rate of $20 \mathrm{sccm}$.

\subsection{UV-visible spectroscopy}

For the transmission measurement, the MLG films have been transferred to the corning glass. Fig. 11 shows the transmittance of MLG on glass substrate in the wavelength range of $300-800 \mathrm{~nm}$. The transmittance (measured at $550 \mathrm{~nm}$ ) is varying from 82 to $91.8 \%$ with the increase of the deposition time. The

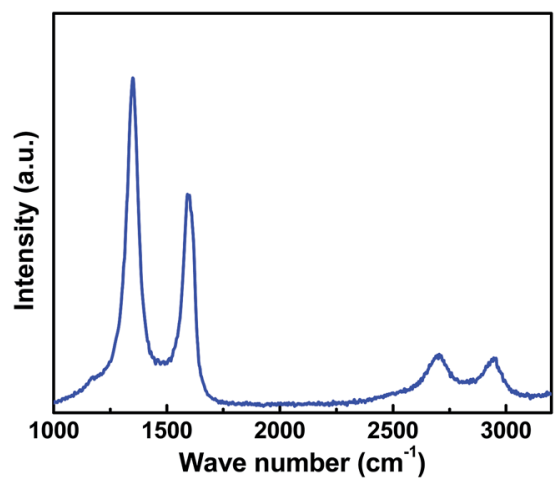

Fig. 10 Raman spectra of CNTs on MLG film deposited with $\mathrm{CH}_{4}$ gas flow rate of $20 \mathrm{sccm}$. 


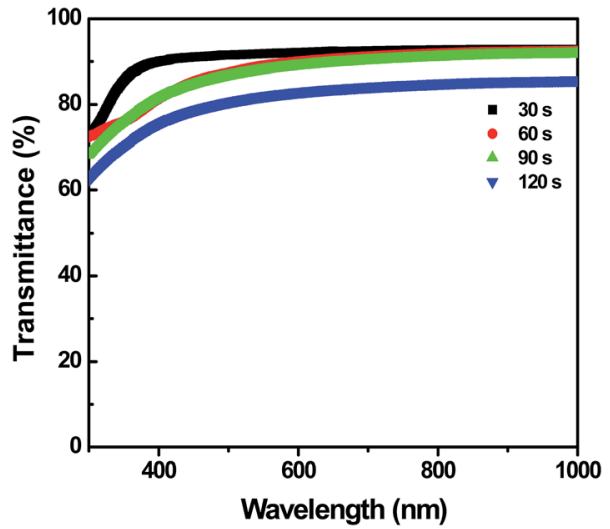

Fig. 11 Transmittance of MLG film deposited at different times, transferred to the glass substrate.

transmittance is correlated to the Raman results which confirm the MLG film.

Optical reflectance can be neglected for few layer graphene. ${ }^{32}$ Li et $a l .{ }^{42}$ have found the application of the CNT/graphene composite film as transparent electrode and found high transmittance $(70-90 \%)$ in the wavelength range $>500 \mathrm{~nm}$ with a strong UV absorption (centered at $250 \mathrm{~nm}$ ) due to the $\pi$ plasmon absorption by CNTs. Due to the high density of CNTs in this work, the film cannot be used as a transparent electrode.

\subsection{Field emission}

The Fowler-Nordheim (F-N) theory is the well-known model to explain field emission from the metal surface and is also applicable to study the field emission behavior of carbon based nanomaterial. The field emission is governed by the FowlerNordheim (F-N) equation. ${ }^{43}$

$$
J=\frac{A(\beta E)^{2}}{\Phi} \exp \left(\frac{-B \Phi^{3 / 2}}{\beta E}\right)
$$

where $J$ is the emission current density, $\Phi$ is the barrier height (taken as the work function), $E$ is the applied electric field, $\beta$ is the field enhancement factor and $A$ and $B$ are constants and have the values of $1.54 \times 10^{-6} \mathrm{~A} \mathrm{~V}^{-2}$ and $6.83 \times 10^{9} \mathrm{~V} \mathrm{~m}^{-1}$ $\mathrm{eV}^{-3 / 2}$, respectively.

Fig. 12 shows the $J-E$ curves of the CNT-MLG films deposited at different methane gas flow rates of (a) $10 \mathrm{sccm}$, (b) $20 \mathrm{sccm}$ and (c) $30 \mathrm{sccm}$, respectively. The inset in Fig. 12(a) shows the schematic of the field emission set up. The field emission measurements have been measured directly on the CNT-MLG film on a copper substrate. The individual MLG has not shown field emission, neither on copper nor on silicon substrate. The turn-on field is defined as the field at which the current density has approached to $10 \mu \mathrm{A} \mathrm{cm} \mathrm{cm}^{-2}$. The turn-on field has been

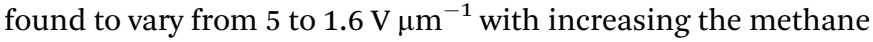
gas flow rates. The maximum current density has been found to be $1.5,2.5$ and $2.8 \mathrm{~mA} \mathrm{~cm}^{-2}$ at methane gas flow rates of 10,20
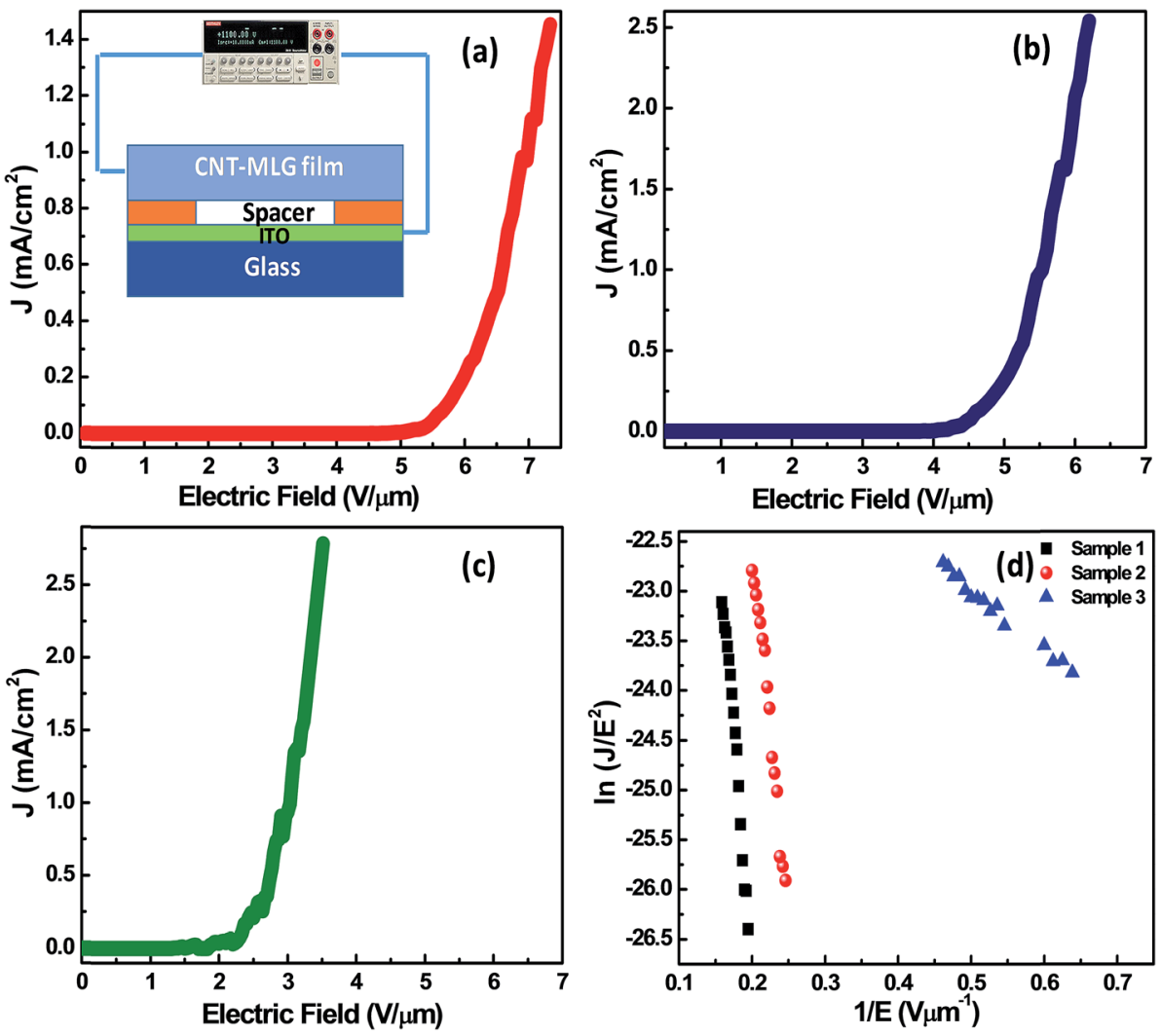

Fig. $12 \mathrm{~J}-E$ plots for the CNT-MLG film deposited at different methane gas flow rates of (a) $10 \mathrm{sccm}$, (b) $20 \mathrm{sccm}$, (c) $30 \mathrm{sccm}$ and (d) their F-N plots. 
and $30 \mathrm{sccm}$, respectively. There are two barriers in the whole process: (i) barrier between the CNT-MLG film and the substrate and (ii) barrier between the CNT-MLG film and the vacuum. Since we have measured the field emission properties directly on $\mathrm{Cu}$ substrate, which have good electrical conductivity, so the barrier between the film and the substrate is expected to be negligible in the whole process. The $\mathrm{F}-\mathrm{N}$ plot between $\ln \left(J / E^{2}\right)$ and $1 / E$ is shown in Fig. 12(d). The linear behaviors of the $\mathrm{F}-\mathrm{N}$ plots have confirmed that the emission process is due to the electron tunneling through the triangular barrier, confirming that the $J-E$ characteristics follow the $\mathrm{F}-\mathrm{N}$ relation. The slopes of these plots give the effective emission barriers $\Phi$, if we assume an ideal plane emitter with a field enhancement factor $\beta$ of 1 . The values of $\Phi$ calculated for the carbon based films were $\leq 0.1 \mathrm{eV}^{44,45}$ These values are obviously quite low and the true barrier may be quite large. ${ }^{46}$ The field enhancement factor $(\beta)$ has been calculated from the slope of the straight line in the F-N plot. The work function of the CNTMLG film has been considered as the individual work function of CNT and graphene $(\sim 5 \mathrm{eV})$. The value of $\beta$ has been found to be 800,1500 and 5540 , respectively, for the sample deposited at different gas flow rates. The image of the phosphor screen during the field emission for the sample deposited using 30 sccm methane gas flow rate is shown in Fig. 13, which reveals that the field emission is uniform.

The field emission properties of the hybrid can be tuned significantly by varying the CNTs density. The field enhancement factor plays an important role in the field emission as it is directly proportional to the local field generated. The value of $\beta$ depends only on the structure of the film. From the SEM micrographs, it is clear that the density of CNTs is increasing with the increase of methane gas flow rates, so the value of $\beta$ is increasing accordingly.

The CNTs network acts as a matrix with the conductive channel, at the same time the MLG acts as an interconnector for the CNTs to enhance the overall electron transport. Nguyen

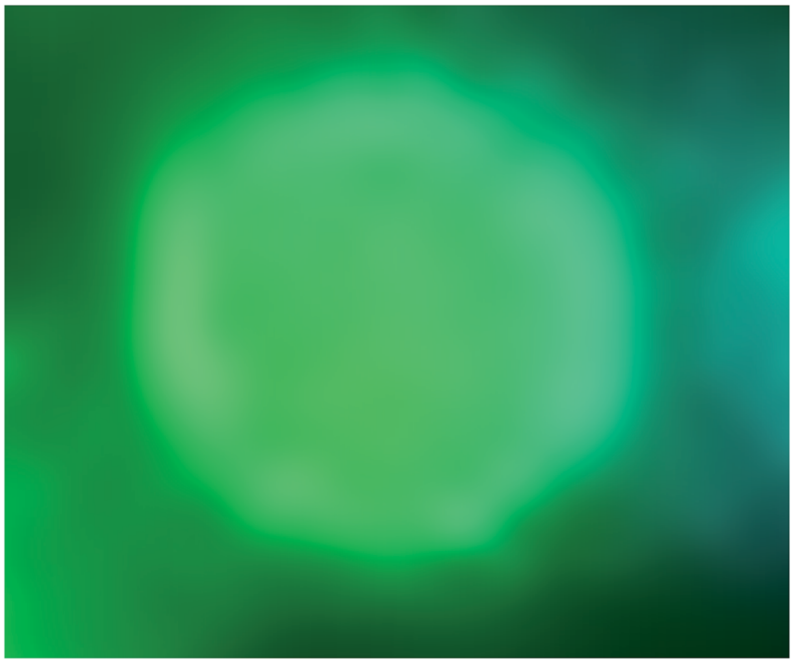

Fig. 13 Image of the phosphor screen during field emission for the sample deposited using $30 \mathrm{sccm}$ methane gas flow rate. et $a l .{ }^{25}$ have measured the field emission properties of the hybrid film and the turn-on field has been found to vary from 10 to $2.9 \mathrm{~V} \mathrm{\mu m}^{-1}$ with varying the density of the CNTs on the graphene. Nguyen et $a .^{47}$ further studied field emission properties of reduced graphene oxide (rGO)-CNT hybrid film with varying CNT density and found the lowest turn on field of $\sim 2.82 \mathrm{~V}$ $\mu \mathrm{m}^{-1}$. Nguyen et al. ${ }^{48}$ have demonstrated that the hybrid film by the low vacuum annealing of cellulose acetate on the nickel show field emission with turn on field of $2.12 \mathrm{~V} \mu \mathrm{m}^{-1}$. The strong physicochemical interaction of graphene interfacial layer with $\mathrm{Cu}$ substrate has contributed the low turn on field. Deng et al. ${ }^{49}$ have deposited catalyst free graphene flakes on the CNT and studied their field emission properties with the lowest turn on field of $0.73 \mathrm{~V} \mu \mathrm{m}^{-1}$. The field emission strongly depends upon the geometric morphology of the emitter. The MLG layer has an advantage of the fast current dissipation, which in turn help to reduce the possibility of the loss of the emission sites due to the Joule heating. ${ }^{50}$

\section{Conclusion}

We have demonstrated a two-step process for the unification of MLG and CNTs on the copper and Si wafer by the MW PECVD technique. MLG was grown on Cu substrate by the MW PECVD technique at a low pressure and transferred to the Si wafer. Optical image and SEM micrographs are confirming the transmittance of the MLG film deposited at different times, which has been found to vary from 82 to $91.8 \%$. Ni nanoparticle assisted CNTs were grown on the MLG both on the $\mathrm{Cu}$ and $\mathrm{Si}$ substrates. The turn on field has been found to vary from 5 to

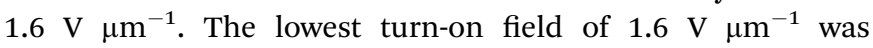
accompanied with the highest current density of $2.8 \mathrm{~mA} \mathrm{~cm}^{-2}$ (at an electric field of $3.5 \mathrm{~V} \mathrm{\mu m}^{-1}$ ) for the CNTs having the highest density.

\section{Acknowledgements}

The authors are grateful to the Director, CSIR-National Physical Laboratory, New Delhi (India), for his kind permission to publish this paper. Mr Atul Bisht and Mr A. K. Kesarwani are grateful to the University Grant Commission (UGC) and Council of Scientific Industrial Research (CSIR), Government of India, New Delhi, respectively, for the financial assistance during the course of this work.

\section{References}

1 S. M. Shinde, G. Kalita, S. Sharma, R. Papon, M. Z. Yusop and M. Tanemura, $R S C$ Adv., 2014, 4, 13355-13360.

2 A. T. T. Koh, T. Chen, L. Pan, Z. Sun and D. H. C. Chua, J. Appl. Phys., 2013, 113, 174909.

3 J. Gong and P. Yang, RSC Adv., 2014, 4, 19622-19628.

4 Y. S. Kim, K. Kumar, F. T. Fisher and E. H. Yang, Nanotechnology, 2012, 23, 015301.

5 S. Vadahanambi, S. H. Lee, W. J. Kim and I. K. Oh, Environ. Sci. Technol., 2013, 47, 10510-10517. 
6 S. Chockalingam, A. Bisht, O. S. Panwar, A. K. Kesarwani, B. P. Singh, J. Chand and V. N. Singh, Mater. Chem. Phys., 2015, 156, 38-46.

7 A. Bisht, S. Chockalingam, O. S. Panwar, A. K. Kesarwani, Ishpal, B. P. Singh and V. N. Singh, Sci. Adv. Mater., 2015, 7, 1424-1434.

8 D. D. Nguyen, R. N. Tiwari, Y. Matsuoka, G. Hashimoto, E. Rokuta, Y. Z. Chen, Y. L. Chueh and M. Yoshimura, ACS Appl. Mater. Interfaces, 2014, 6, 9071-9077.

9 S. H. Jeong, H. Y. Hwang, K. H. Lee and Y. Jeong, Appl. Phys. Lett., 2001, 78, 2052-2054.

10 G. Mittal, M. Khaneja, K. Sain and I. I. Lahiri, $R S C A d v ., 2015$, 5, 21487-21494.

11 W. I. Milne, K. B. K. Teo, G. A. J. Amaratunga, P. Legagneux, L. Gangloff, J. P. Schnell, V. Semet, V. Thien Binh and O. Groening, J. Mater. Chem., 2004, 14, 933-943.

12 K. A. Cao, P. L. Dickrell, W. G. Sawyer, M. N. G. Nejhad and P. M. Ajayan, Science, 2005, 310, 1307-1310.

13 D. Wei, Y. Liu, Y. Wang, H. Zhang, L. Huang and G. Yu, Nano Lett., 2009, 9, 1752-1758.

14 J. Gong and P. Yang, RSC Adv., 2014, 4, 19622-19628.

15 E. S. Polsen, D. Q. McNerny, B. Viswanath, S. W. Pattinson and A. J. Hart, Sci. Rep., 2015, 5, 10257.

16 C. Yan, J. H. Cho and J. H. Ahn, Nanoscale, 2012, 4, 48704882.

17 G. Kalita, K. Wakita and M. Umeno, $R S C A d v .$, 2012, 2, 28152820.

18 D. A. Boyd, W. H. Lin, C. C. Hsu, M. L. Teague, C. C. Chen, Y. Y. Lo, W. Y. Chan, W. B. Su, C. S. Chang, C. I. Wu, N. C. Yeh and T. C. Cheng, Nat. Commun., 2015, 6, 6620.

19 Y. Okigawa, K. Tsugawa, T. Yamada, M. Ishihara and M. Hasegawa, Appl. Phys. Lett., 2013, 103, 153106.

20 M. Taniguchi, H. Nagao, M. Hiramatsu, Y. Ando and M. Hori, Diamond Relat. Mater., 2005, 14, 855-858.

21 F. Fendrych, A. Taylor, L. Peksa, I. Kratochvilova, J. Vlcek, V. Rezacova, V. Petrak, Z. Kluiber, L. Fekete, M. Liehr and M. Nesladek, J. Phys. D: Appl. Phys., 2010, 43, 374018.

22 Z. Bo, Y. Yang, J. Chen, K. Yu, J. Yan and K. Cen, Nanoscale, 2013, 5, 5180-5204.

23 N. Woehrl, O. Ochedowski, S. Gottlieb, K. Shibasaki and S. Schulz, AIP Adv., 2014, 4, 047128.

24 H. Zhuang, B. Yang, L. Zhang, S. Heuser and X. Jiang, Carbon, 2015, 95, 824-832.

25 D. D. Nguyen, N. H. Tai, S. Y. Chen and Y. L. Chueh, Nanoscale, 2012, 4, 632-638.

26 S. Das, R. Seelaboyina, V. Verma, I. Lahiri, J. Y. Hwang, R. Banerjee and W. Choi, J. Mater. Chem., 2011, 21, 72897295.

27 H. Xie, R. Zhang, Y. Zhang, W. Zhang, M. Jian, C. Wang, Q. Wang and F. Wei, Chem. Commun., 2014, 50, 1115811161.

28 K. Kumar, Y. S. Kim, X. Li, J. Ding, F. T. Fisher and E. H. Yang, Chem. Mater., 2013, 25, 3874-3879.
29 D. H. Lee, J. E. Kim, T. H. Han, J. W. Hwang, S. Jeon, S. Y. Choi, S. H. Hong, W. J. Lee, R. S. Ruoff and S. O. Kim, Adv. Mater., 2010, 22, 1247-1252.

30 X. Dong, B. Li, A. Wei, X. Cao, M. B. C. Park, H. Zhang, L. J. Li, W. Huang and P. Chen, Carbon, 2011, 49, 2944-2952.

31 C. Mattevi, H. Kim and M. Chhowalla, J. Mater. Chem., 2011, 21, 3324-3334.

32 K. J. Peng, Y. H. Pai, C. L. Wu, G. R. Lin, Y. H. Lin, Y. J. Liu and D. P. Tsai, J. Mater. Chem. C, 2013, 1, 3862-3870.

33 E. Thouti, N. Chander, V. Dutta and V. K. Komarala, J. Opt., 2013, 15, 035005.

34 J. H. Choi, T. Y. Lee, S. H. Choi, J. H. Han, J. B. Yoo, C. Y. Park, T. Jung, S. G. Yu, W. Yi, I. T. Han and J. M. Kim, Diamond Relat. Mater., 2003, 12, 794-798.

35 Y. Wang, Z. Luo, B. Li, P. S. Ho, Z. Yao, L. Shi, E. N. Bryan and R. J. Nemanich, J. Appl. Phys., 2007, 101, 124310.

36 M. Meyyappan, L. Delzeit, A. Cassell and D. Hash, Plasma Sources Sci. Technol., 2003, 12, 205-216.

37 G. Lombardi, K. Hassouni, G. D. Stancu, L. Mechold, J. Röpcke and A. Gicquel, J. Appl. Phys., 2005, 98, 053303.

38 H. Zhuang, L. Zhang, T. Staedler and X. Jiang, Scr. Mater., 2011, 65, 548-551.

39 O. S. Panwar, A. K. Kesarwani, S. R. Dhakate, B. P. Singh, R. K. Rakshit, A. Bisht and S. Chockalingam, J. Vac. Sci. Technol., B: Nanotechnol. Microelectron.: Mater., Process., Meas., Phenom., 2013, 31, 040602.

40 A. K. Kesarwani, O. S. Panwar, S. Chockalingam, A. Bisht, S. R. Dhakate, B. P. Singh, A. K. Srivastava and R. K. Rakshit, Sci. Adv. Mater., 2014, 6, 2124-2133.

41 Y. Kim, W. Song, S. Y. Lee, C. Jeon, W. Jung, M. Kim and C. Y. Park, Appl. Phys. Lett., 2011, 98, 263106.

42 C. Li, Z. Li, H. Zhu, K. Wang, J. Wei, X. Li, P. Sun, H. Zhang and D. Wu, J. Phys. Chem. C, 2010, 114(33), 14008-14012.

43 R. H. Fowler and L. Nordheim, Proc. R. Soc. London, Ser. A, 1928, 119, 173-181.

44 O. S. Panwar, S. Kumar, S. S. Rajput, R. Sharma and R. Bhattacharyya, Vacuum, 2004, 72, 183-192.

45 O. S. Panwar, M. A. Khan, B. S. Satyanarayana, R. Bhattacharyya, B. R. Mehta, S. Kumar and Ishpal, J. Vac. Sci. Technol., B: Nanotechnol. Microelectron.: Mater., Process., Meas., Phenom., 2010, 28, 411-422.

46 O. S. Panwar, N. Rupesinghe and G. A. J. Amaratunga, J. Vac. Sci. Technol., B: Microelectron. Nanometer Struct.-Process., Meas., Phenom., 2008, 26, 566-575.

47 D. D. Nguyen, Y. T. Lai and N. H. Tai, Diamond Relat. Mater., 2014, 47, 1-6.

48 D. D. Nguyen, R. N. Tiwari, Y. Matsuoka, G. Hashimoto, E. Rokuta, Y. Z. Chen, Y. L. Chueh and M. Yoshimura, ACS Appl. Mater. Interfaces, 2014, 6, 9071-9077.

49 J. H. Deng, G. A. Cheng, R. T. Zheng, B. Yu, G. Z. Li, X. G. Hou, M. L. Zha and D. J. Li, Carbon, 2014, 67, 525-533.

50 J. H. Deng, B. Yu, G. Z. Li, X. G. Hou, M. L. Zhao, D. J. Li, R. T. Zheng and G. A. Cheng, Nanoscale, 2013, 5, 1238812393. 